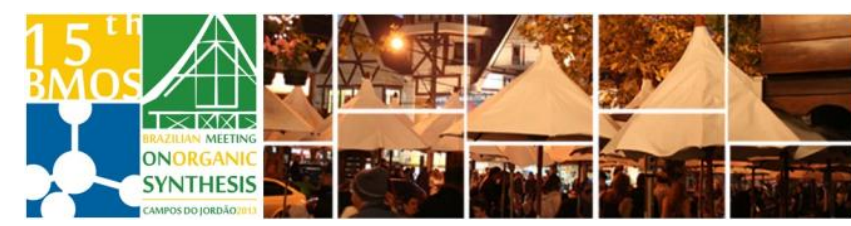

\title{
Enantioselective Arylation of Aliphatic Aldehydes Catalyzed by Chiral Amino Alcohols derived from Amino Acids
}

\section{Maria Eduarda Contreira (PG)* e Diogo Seibert Lüdtke (PQ)}

Institute of Chemistry, Federal University of Rio Grande do Sul (UFRGS), Av. Bento Gonçalves 9500,

\author{
CEP: 91501-970, Porto Alegre, Rio Grande do Sul, Brasil.
}

*e-mail corresponding author: dudacontreira@gmail.com

Keywords: amino alcohols, amino acids, asymmetric catalysis.

\section{INTRODUCTION}

Chiral secondary alcohols are important tools in organic chemistry, because they are precursors blocks of several natural products and drugs. ${ }^{1}$

One of the most studied methods for obtaining these alcohols is the catalytic asymmetric arylation of aldehydes, where the use of the reaction of boron-zinc exchange, generating reactive aryl zinc species stands out as one of the most interesting methods for selective transfer of aryl, as arylboronic compounds may be obtained commercially or readily synthesized. ${ }^{2}$

In this context, we report herein preliminary results of our studies on the enantioselective arylation of aliphatic aldehydes using as chiral ligands, amino alcohols derived from amino acids $L$ phenylalanine, $L$-valine and $L$-proline.

\section{RESULTS AND DISCUSSION}

To determine the best reaction conditions, we tested the ligand L1 (Figure 1), with hexanal in toluene varying parameters of temperature, time and amount of ligand in $\mathrm{mol} \%$.

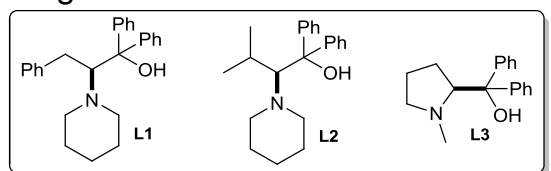

Figure 1. Chiral ligands derived from amino acids of $L$ phenylalanine, $L$-valine and $L$-proline respectively.

First, tests were conducted using a temperature of $0^{\circ} \mathrm{C}$. Analyzing the reaction time for the formation of reactive species arylzinc with one hour (Table 1, entry 1) and 30 minutes (entry 2), it was found that the yields and the ee are not varied and increasing the reaction time for the formation of the chiral alcohol one hour to two hours was observed an increase in yield, however, a reduction in ee (entries 1 and 3 ). The reduction of the amount of the ligand $\mathrm{L} 1$ to $15 \mathrm{~mol} \%$ (entry 6 ) promoted a decrease in yield and ee. In order to increase the ee, we tested the reaction at low temperatures (entries 4 and 5), however, was observed a decrease in yield and in the ee.

Defined best reaction parameters 30 minutes to exchange reaction boron-to-zinc at $60{ }^{\circ} \mathrm{C}, 20 \mathrm{~mol} \%$ ligand for 15 minutes at room temperature and $0{ }^{\circ} \mathrm{C}$ for one hour to form the chiral alcohol, were tested ligands L2 and L3 (Figure 1), and both showed a reduction in ee and yield (entries 7 and 8 ).

Table 1. Enantioselective arylation of Aliphatic aldehydes.

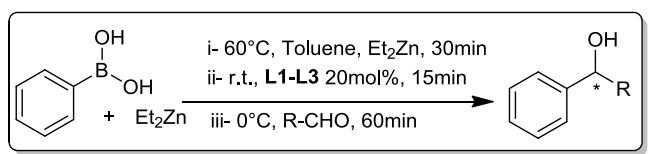

\begin{tabular}{|c|c|c|c|c|}
\hline Entry & $\mathbf{R}$ & Ligand & ee \% & Yield \% \\
\hline $1^{a}$ & $\mathrm{C}_{5} \mathrm{H}_{11} \mathbf{1 a}$ & $L_{1}$ & 60 & 80 \\
\hline 2 & 1a & $L_{1}$ & 60 & 80 \\
\hline $3^{b}$ & $1 a$ & $\mathrm{~L}_{1}$ & 50 & 85 \\
\hline $4^{c}$ & $1 a$ & $L_{1}$ & 55 & 60 \\
\hline $5^{d}$ & $1 a$ & $L_{1}$ & 40 & 24 \\
\hline $6^{e}$ & $1 a$ & $L_{1}$ & 36 & 74 \\
\hline 7 & $1 a$ & $\mathrm{~L}_{2}$ & 36 & 60 \\
\hline 8 & $1 a$ & $\mathrm{~L}_{3}$ & 45 & 60 \\
\hline 9 & cyclohexyl & $L_{1}$ & 70 & 96 \\
\hline 10 & $\mathrm{C}_{7} \mathrm{H}_{15}$ & $\mathrm{~L}_{1}$ & 55 & 60 \\
\hline 11 & $\mathrm{C}_{9} \mathrm{H}_{19}$ & $L_{1}$ & 43 & 14 \\
\hline 12 & $\left(\mathrm{CH}_{3}\right)_{2} \mathrm{CH}$ & $L_{1}$ & 60 & 43 \\
\hline
\end{tabular}

Thus was found the best reaction conditions using ligand $L_{1}$ (Table 1, entry 2 ). Then, the reaction scope can be extended to other aliphatic aldehydes (Table 1, entries 9-12) giving yields and ee moderate to good.

\section{CONCLUSION}

The enantioselective arylation of aliphatic aldehydes catalyzed by amino alcohols derived from amino acids was described. Studies using other aliphatic aldehydes and substituted phenylboronic acids will be employed.

\section{ACKNOWLEDGEMENTS}

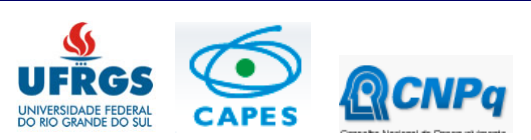

FAPERGS

\section{REFERENCES}

${ }^{1}$ Wu, N.; Bo, R.; Zhang, R.; Jiang, X.; Wan, Y.; Xu, Z.; Wu, H. Letters in Organic Chemistry. 2012, 9, 644-649.

${ }^{2}$ Wouters, A. D.; Trossini, G. H. G.; Stefani, H. A.; Lüdtke, D. S. Eur. J. Org. Chem. 2010, 2351-2356. 